\title{
A CASE OF A GIANT EPIPHRENIC ESOPHAGEAL DIVERTICULUM
}

\author{
G. Yankov', E. Mekov' ${ }^{1}$ M. Kovacheva ${ }^{2}$, B. Vladimirov², R. Petkov ${ }^{1}$ \\ ${ }^{1}$ Department of Respiratory Diseases, Medical Faculty, Medical University - Sofia, Bulgaria \\ ${ }^{2}$ Department of Gastroenterology, Medical Faculty, Medical University - Sofia, Bulgaria
}

\begin{abstract}
The esophageal diverticula are divided into pharyngoesophageal, parabronchial and epiphrenic. They could also be divided into congenital and acquired, true and false, pulsion and traction. Pulsion diverticula are usually formed in motor disorders of the esophagus, above the place of hypertension and uncoordinated peristalsis. They are pseudodiverticula caused by increased intramural pressure, leading to herniation of the mucosa and submucosa through the focal areas of the esophageal wall. We present a 65-year-old woman who underwent left-sided transthoracic diverticulectomy, modified Heller esophagocardiomyotomy, and modified Belsey-Mark IV fundoplication due to a huge epiphrenic esophageal diverticulum.
\end{abstract}

Key words: epiphrenic diverticula, myotomy, diverticulectomy, antireflux procedure

Corresponding author: MHATPD „Sveta Sofia“, 1431, 19, „Acad. Ivan Geshov“ blvd, Sofia, Bulgaria. tel. +359 888320 476, e-mail: evgeni.mekov@gmail.com

\section{INTRODUCTION}

T he esophageal diverticula are divided into pharyngoesophageal, parabronchial and epiphrenic. In very rare cases, diffuse intramural diverticulosis is observed. They could also be divided into congenital and acquired, true and false, pulsion and traction. Pulsion diverticula are usually formed in motor disorders of the esophagus, above the place of hypertension and uncoordinated peristalsis. They are pseudodiverticula caused by increased intramural pressure, leading to herniation of the mucosa and submucosa through the focal areas of the esophageal wall [1]. The most common diverticula in developed countries are pulsions [2]. Traction diverticula are most often a result of an inflammatory process and are located in the middle part of the esophagus near the bifurcation, often in tuberculous or nonspecific lymphadenitis. Most diverticula are acquired.
The epiphrenic diverticula are usually located in the lower third of the esophagus, near the diaphragm and about $10-15 \mathrm{~cm}$ above the lower esophageal sphincter, and are associated with a motor disorder of the esophagus. They could be associated with achalasia, diffuse esophageal spasm, and hiatal hernia. The indications, access, and type of surgical procedure are still discussed, but the pathophysiological principles must be considered [3].

\section{CASE REPORT}

We present a case of a 65 -year-old woman who was admitted to the Thoracic Surgery Department with complaints of nausea, chest pain, and frequent vomiting starting 3 months ago. The past medical history was remarkable for Hashimoto's thyroiditis.

On fibroesophagogastroscopy, a large diverticulum filled with food particles was visualized, located 34 
$\mathrm{cm}$ from the dentition. The opening of the esophagus in this part was about $30 \mathrm{~mm}$. Visible gastric and duodenal mucosa were unremarkable.

Contrasting esophagography showed $\mathrm{X}$-ray data for a huge diverticulum up to $10 \mathrm{~cm}$ in the distal third of the esophagus (Fig. 1). Contrast material passed into the stomach after short retention.

The CT showed a dilated esophagus with a large pulsion diverticulum in the distal third, located on the right side of the mediastinum, which was about $10 \mathrm{~cm}$ in diameter (Fig. 2).

The distal third of the esophagus was mobilized through left-sided lateral thoracotomy along VI intercostal space, which in the cranial direction was strongly dilated and atonic. A large diverticulum measuring about $10 \mathrm{~cm}$ in diameter, located to the right of the midline, was located distal to the described site. The latter was sharp dissected and released from the surrounding tissues (Fig. 3). The width of the diverticulum cervix was about $4.0 \mathrm{~cm}$. Distal to the diverticulum a spastic esophagus was found. The cardia was dissected from the diaphragm hiatus. Diverticulum resection was performed and the esophageal wall was sutured with an interrupted suture (Fig. 4A). The suture line was buttressed with the previously constructed intercostal musculopleural flap (Fig. 4B). From the level of onset of the descending thoracic aorta up to $1.5 \mathrm{~cm}$ below the cardia, esophagocardiomyotomy was performed. A modified Belsey-Mark IV fundoplication with two rows of mattress silk stitches and cruroraphy was carried out (Fig. 5).

Histological examination showed a diverticulum wall with pronounced non-specific inflammatory process and focal infiltration with lymphocytes, eosinophilic leukocytes, plasma cells and vessels filled with neutrophilic leukocytes. The presence of detrital matter was also noted.

The postoperative period was uneventful.

\section{DISCUSSION}

In giant diverticula, as well as in patients with significant symptoms, as the presented case, surgical

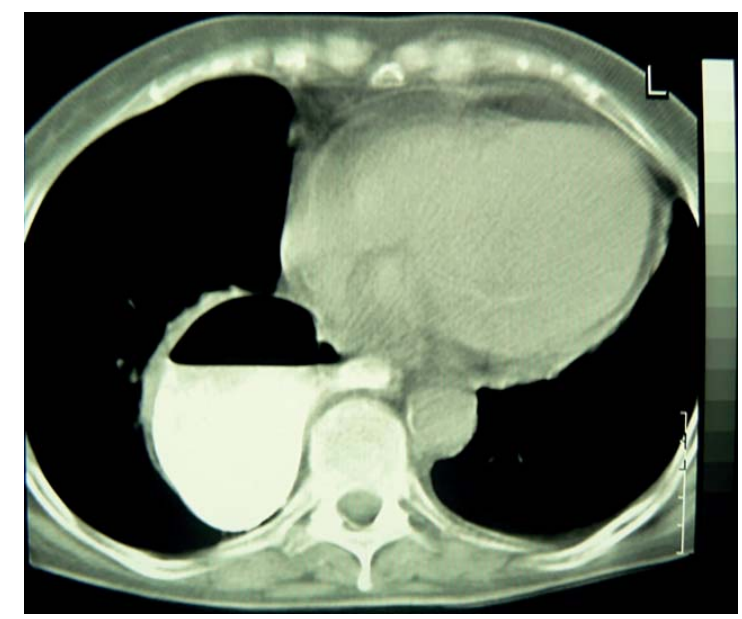

Fig. 2. Chest CT

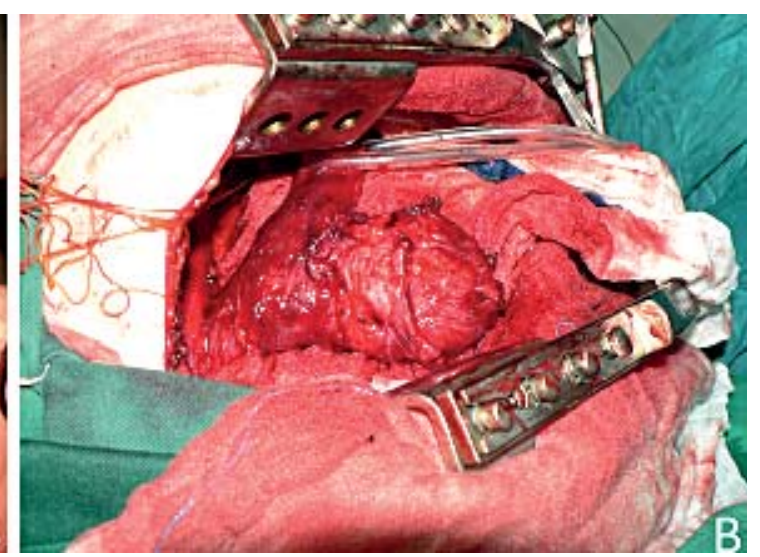

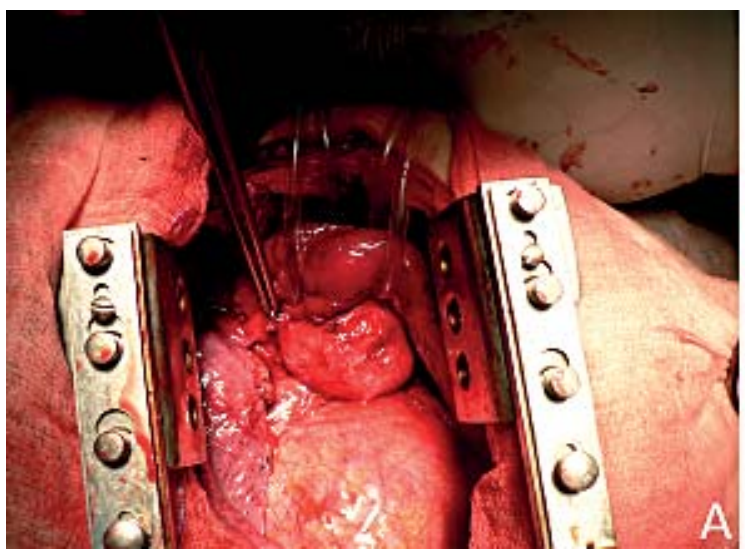

Fig. 3. Diverticulum dissected from surrounding structures 

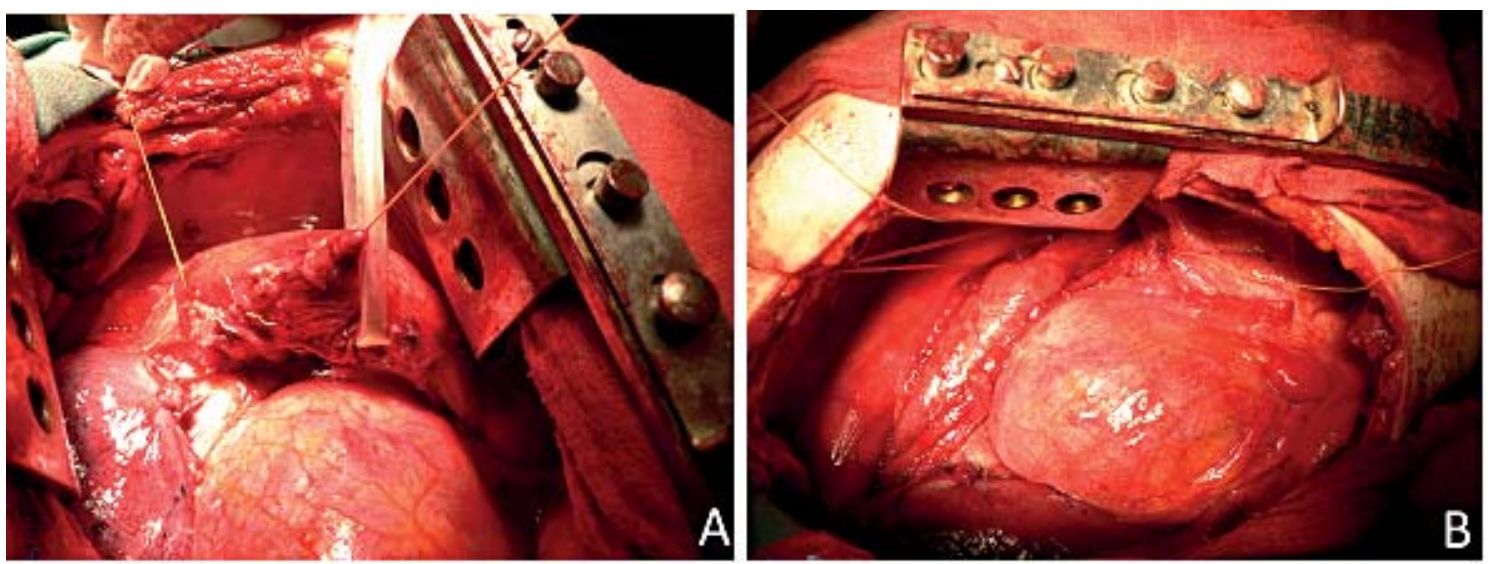

Fig. 4. A - Diverterculectomy, B - Esophagocardiomyotomy
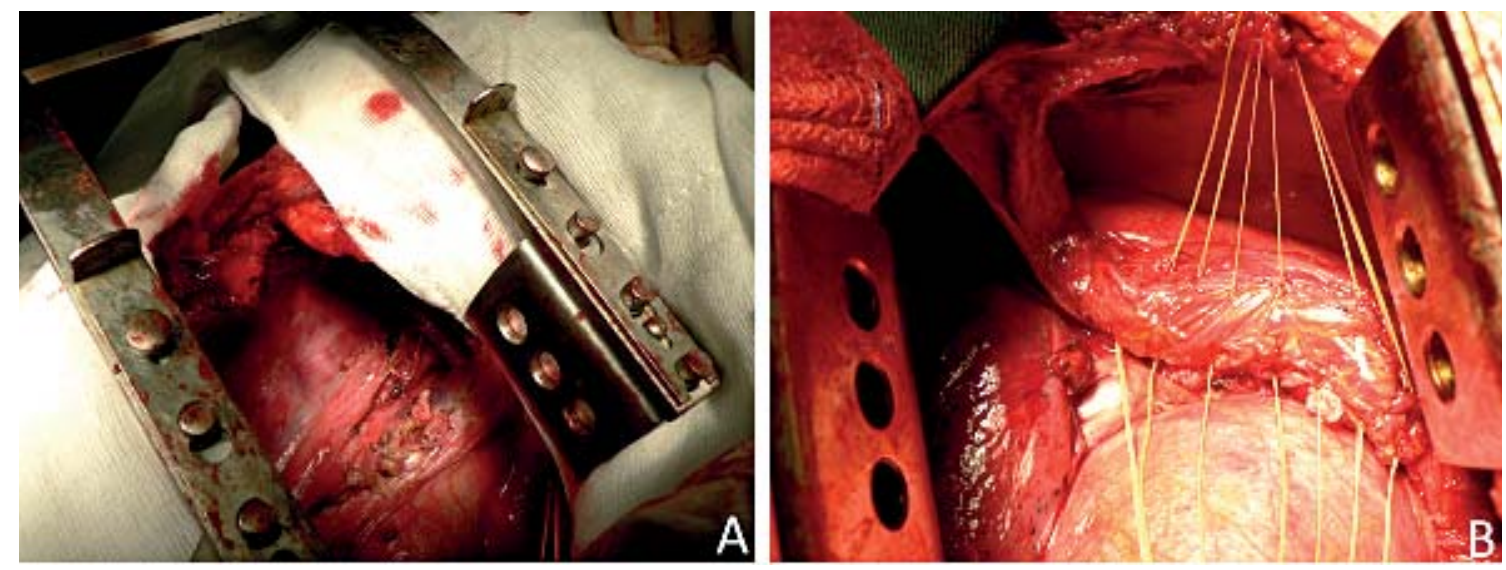

Fig. 5. A - Belsey-Mark IV antireflux procedure. B - Buttressing of the suture line with intercostal muscle flap

treatment is the method of choice because of impaired quality of life and the risk of complications. Complications in non-operated patients include diverticulitis, perforation, fistulization in the aorta or the pleura, hemorrhage, severe reflux with aspiration pneumonia, and cancer in the diverticulum, which is extremely rare. The indications for surgery in asymptomatic patients or patients with minimal symptoms are unclear [4].

Regarding the access, whether a myotomy should be performed, how long should it be, and is the addition of antireflux surgery appropriate, are issues that are still under discussion. One of the largest studies uses classic transthoracic access, diverticulectomy, long myotomy, and antireflux surgery in 33 patients [5]. Minimally invasive procedures are also safe and effective, especially when performed by experienced surgeons [6]. According to Tapias et al., minimally invasive approaches should be considered individually for each patient as they are associated with higher levels of complications, especially esophageal leaks [7]. They prefer a transthoracic approach with man- datory diverticulectomy and myotomy while performing antireflux surgery remains controversial. Caronia et al. performed uniportal video-assisted thoracoscopic resection of a giant diverticulum, myotomy, and Belsey-Mark IV antireflux procedure in a patient with an esophageal leak on the 15th postoperative day, but the complication was resolved with stent placement [8]. Resection of esophageal diverticulum by thoracoscopy in a prone position has several advantages and routine myotomy for the middle onethird diverticula is not advised, given the risk of poor functional results and diverticulization of the myotomy itself [9]. Soares et al. recommend a transthoracic approach of the diverticulum, especially if it is located 8-10 cm above the gastroesophageal junction since the upper cervix is more difficult for laparoscopic dissection [10].

In such patients, especially with giant or right-sided diverticula, we also recommend left-sided transthoracic access. This approach gives better access to the hiatus and the opportunity to perform an antireflux procedure, which is often necessary, especially 
in hypertensive and non-relaxing lower esophageal sphincter. The suture line could be enhanced with an intercostal muscle flap for esophageal leak prevention, as was done in the presented case. Thoracoscopic access provides better visualization and easier dissection than laparoscopic, especially in higher diverticula, but creates difficulties if antireflux surgery is needed. The latter could be supplemented by laparoscopic antireflux surgery when required [6]. Access with laparoscopy and thoracoscopy significantly prolongs the intervention and requires penetration into two body cavities. The individual judgment and approach in each patient are crucial for a successful outcome in this pathology.

Disclosure Summary: The authors have nothing to disclose.

\section{REFERENCES}

1. Belsey R. Functional disease of the esophagus. J Thorac Cardiovasc Surg1966;52:164-88.

2. Thomas ML, Anthony AA, Fosh BG et al. Oesophageal diverticula. Br J Surg 2001;88:629-62.

3. Reznik SI, Rice TW, Murthy SC et al. Assessment of a pathophysiology-directed treatment for symptomatic epiphrenic diverticulum. Dis Esophagus 2007;20(4):320-7.
4. Altorki NK, Sunagawa M, Skinner DB. Thoracic esophageal diverticula. Why is operation necessary? J Thorac Cardiovasc Surg 1993;105(2):260-4.

5. Varghese TK Jr, Marshall B, Chang AC et al. Surgical treatment of epiphrenic diverticula: a 30-year experience. Ann Thorac Surg 2007;84(6):1801-9.

6. Macke RA, Luketich JD, Pennathur A, et al. Thoracic esophageal diverticula: a 15-year experience of minimally invasive surgical management. Ann Thorac Surg 2015;100(5):1795-802.

7. Tapias LF, Morse CR, Mathisen DJ, et al. Surgical management of esophageal epiphrenic diverticula: a transthoracic approach over four decades. Ann Thorac Surg 2017;104(4):1123-30.

8. Caronia FP, Fiorelli A, Santini M, Monte Al Lo. Uniportal video-assisted thoracoscopic surgery resection of a giant midesophageal diverticulum. Ann Thorac Surg 2017;103(4):e365-e367.

9. Chandeze M-M, Gayet B, Cowan J et al. Resection of an esophageal diverticulum by thoracoscopy in prone position. Ann Thorac Surg 2019;107(2):e153-e156.

10. Soares R, Herbella FA, Prachand VN et al. Epiphrenic diverticulum of the esophagus. From pathophysiology to treatment. J Gastrointest Surg 2010;14(12):2009-15.

Received: February, 2019 - Accepted: February, 2019 